\title{
Footprinting analysis of BWYV pseudoknot-ribosome complexes
}

\author{
MARIE-HÉLÈNE MAZAURIC, ${ }^{1}$ JEAN-LOUIS LEROY, ${ }^{1}$ KOEN VISSCHER, ${ }^{2,3,4}$ SATOKO YOSHIZAWA, ${ }^{1}$ \\ and DOMINIQUE FOURMY \\ ${ }^{1}$ Laboratoire de Chimie et Biologie Structurales, FRC3115, ICSN-CNRS, Gif-sur-Yvette 91190, France \\ ${ }^{2}$ Department of Physics, University of Arizona, Tucson, Arizona 85721, USA \\ ${ }^{3}$ Department of Molecular and Cellular Biology, University of Arizona, Tucson, Arizona 85721, USA \\ ${ }^{4}$ College of Optical Sciences, University of Arizona, Tucson, Arizona 85721, USA
}

\begin{abstract}
Many viruses regulate translation of polycistronic mRNA using a -1 ribosomal frameshift induced by an RNA pseudoknot. When the ribosome encounters the pseudoknot barrier that resists unraveling, transient mRNA-tRNA dissociation at the decoding site, results in a shift of the reading frame. The eukaryotic frameshifting pseudoknot from the beet western yellow virus (BWYV) has been well characterized, both structurally and functionally. Here, we show that in order to obtain eukaryotic levels of frameshifting efficiencies using prokaryotic Escherichia coli ribosomes, which depend upon the structural integrity of the BWYV pseudoknot, it is necessary to shorten the mRNA spacer between the slippery sequence and the pseudoknot by 1 or 2 nucleotides (nt). Shortening of the spacer is likely to re-establish tension and/or ribosomal contacts that were otherwise lost with the smaller $E$. coli ribosomes. Chemical probing experiments for frameshifting and nonframeshifting BWYV constructs were performed to investigate the structural integrity of the pseudoknot confined locally at the mRNA entry site. These data, obtained in the pretranslocation state, show a compact overall pseudoknot structure, with changes in the conformation of nucleotides (i.e., increase in reactivity to chemical probes) that are first "hit" by the ribosomal helicase center. Interestingly, with the 1-nt shortened spacer, this increase of reactivity extends to a downstream nucleotide in the first base pair (bp) of stem 1, consistent with melting of this base pair. Thus, the 3 bp that will unfold upon translocation are different in both constructs with likely consequences on unfolding kinetics.
\end{abstract}

Keywords: translocation; BWYV; frameshifting; mRNA; translation

\section{INTRODUCTION}

During protein synthesis the ribosome reads successive codons on the mRNA maintaining the correct reading frame (Ogle and Ramakrishnan 2005). Efficient triplet decoding is achieved by the coordinated movement of tRNA and associated mRNA through the ribosome by means of a universally conserved mechanism called translocation (Noller et al. 2002). Under normal circumstances frameshift errors are rare, occurring at a rate of less than once per $10^{5}$ codons (Kurland 1992). Folded structures (pseudoknots or simple stem-loops) within the coding regions of mRNA are able

Reprint requests to: Dominique Fourmy, Laboratoire de Chimie et Biologie Structurales FRC3115, ICSN-CNRS, 1 Avenue de la Terrasse, Gif-sur-Yvette 91190, France; e-mail: fourmy@icsn.cnrs-gif.fr; fax: 33-169823784; or Satoko Yoshizawa, Laboratoire de Chimie et Biologie Structurales FRC3115, ICSN-CNRS, 1 Avenue de la Terrasse, Gif-sur-Yvette 91190, France; e-mail: yoshizawa@icsn.cnrs-gif.fr; fax: 33-1-69823784.

Article published online ahead of print. Article and publication date are at http://www.rnajournal.org/cgi/doi/10.1261/rna.1385409. to stimulate a change in the reading frame (Jacks et al. 1988; Brierley et al. 1989). The translating ribosome shifts into the -1 reading frame at a heptanucleotide sequence XXXYYYZ called the slippery sequence (the bases X and Y can be identical). The length and sequence of a spacer region linking the slippery sequence and the downstream stimulatory RNA further controls frameshifting efficiency (Brierley et al. 1989; Kollmus et al. 1994; Kim et al. 2001; Bertrand et al. 2002). The stimulatory element is, in most cases, a hairpin (H)-type pseudoknot (Giedroc et al. 2000; Baranov et al. 2002) or more rarely a stem-loop (Dulude et al. 2002; Gaudin et al. 2005; Staple and Butcher 2005b; Marcheschi et al. 2007). An H-type pseudoknot (Fig. 1) is formed by base pairing between nucleotides in a hairpin loop with nucleotides in a single-stranded region outside the hairpin (Pleij et al. 1985; Puglisi et al. 1988; Su et al. 1999; Staple and Butcher 2005a). Fine tuning of the slippery sequence, spacer, and stimulatory action of the downstream structural RNA element results in frameshifting efficiency that is considerably above the basal level of frameshifting errors in the cell. 


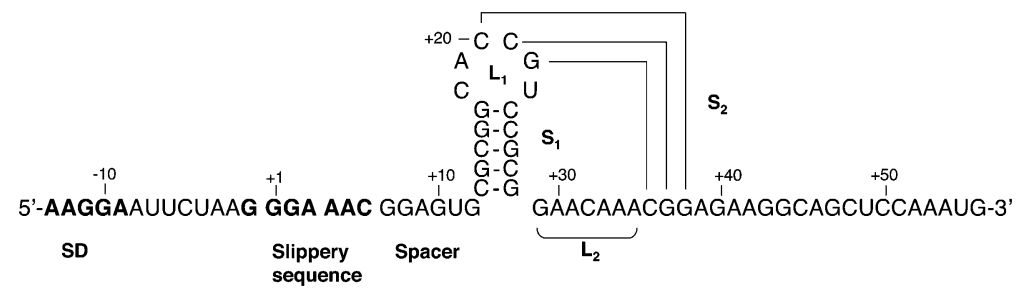

FIGURE 1. Secondary structure of the mRNA containing the BWYV pseudoknot. Secondary structural elements are labeled: stems (S) and loops (L). The slippery and Shine-Dalgarno (SD) sequences are in bold.

The crystal structure of the ribosome in complex with mRNA has revealed that the mRNA is in a single-stranded conformation in the narrow downstream tunnel (Yusupova et al. 2001; Jenner et al. 2007). The ribosome is therefore required to unwind mRNA secondary structure and it has been shown that the ribosome itself is an mRNA helicase (Takyar et al. 2005). A mechanistic basis for mRNA helicase activity has been proposed, which involves ribosomal proteins S3, S4, and S5 at the mRNA entrance and rotational movement of the head of the $30 \mathrm{~S}$ subunit (Yusupova et al. 2001; Takyar et al. 2005). The helicase activity is directly coupled to the mechanism of translocation (Wen et al. 2008), which may involve several types of movements within the ribosome (Schuwirth et al. 2005; Horan and Noller 2007). Downstream structural RNA elements near the ribosome entry site may therefore stimulate frameshifting at the slippery site by presenting a physical barrier to the mRNA translocation machinery. The -1 frameshifting $(-1 \mathrm{FS})$ is likely dependent upon mechanical tension induced by the folded pseudoknot against the translating ribosome (Plant and Dinman 2005). Consistent with this hypothesis, cryoelectron microscopic images of eukaryotic ribosomes stalled in complex with eEF2, tRNA, and a frameshifting mRNA pseudoknot showed a deformed P-site tRNA (Namy et al. 2006).

Despite extensive functional and structural studies (Shen and Tinoco 1995; Du et al. 1997; Marczinke et al. 1998; Kim et al. 1999, 2000; Su et al. 1999; Michiels et al. 2001; Nixon et al. 2002; Baril et al. 2003; Giedroc et al. 2003; Cornish et al. 2005; Pallan et al. 2005), the mechanism by which pseudoknots promote -1FS remains largely unclear (Giedroc and Cornish 2009). For example, frameshift efficiencies do not correlate with the thermodynamic stability of the pseudoknots (Chen et al. 1995; Napthine et al. 1999), as structurally similar pseudoknots display a wide range of frameshifting efficiencies (Chen et al. 1995; Kim et al. 1999, 2000; Cornish et al. 2005), Thus, -1FS seems more likely to be kinetically controlled (Cornish et al. 2006), as recently suggested by mechanical unfolding experiments of frameshifting pseudoknots and their constituent hairpins (Chen et al. 2007; Hansen et al. 2007; Green et al. 2008).

An effect not addressed by any of these studies, but one that is also likely to affect -1 FS efficiencies is the direct contacts between the pseudoknot and the translational machinery. For example, it has been recently found that a sequence of poly(U), known to lack any structure in solution (Seol et al. 2004), can adopt a well-defined three-dimensional structure by contacting ribosomal protein S2 (Yusupova et al. 2006). It is conceivable that ribosomal proteins $\mathrm{S} 3, \mathrm{~S} 4$, and $\mathrm{S} 5$, e.g., which are at the mRNA entry site, or other ribosomal components, may similarly affect the conformation of the mRNA. However, the interactions of pseudoknots with the ribosome, as they approach the mRNA entry site during elongation cycles, remain uncharacterized. In particular, identification of possible intermolecular contacts, at singlenucleotide resolution is lacking. Moreover, it is not known if those putative contacts occur in the pretranslocation state or "on-pathway" during translocation. Also, the spacer sequence may well start to adopt an extended conformation as early as at the pretranslocation state when the pseudoknot approaches the ribosomal surface. Thus, the precise conformation of the pseudoknot at this stage remains unknown. Therefore, our goal was to evaluate the effect of the ribosomal environment at the mRNA entry site on the structure of the pseudoknot and to identify possible intermolecular contacts by using RNA chemical probing and footprinting analysis. We used the BWYV RNA pseudoknot (Fig. 1) for our investigation because it has been extensively characterized, both structurally and functionally ( $\mathrm{Su}$ et al. 1999; Egli et al. 2002). Most of the previous mRNA footprinting analyses on the ribosome utilized Escherichia coli ribosomes. To compare with the existing data we developed a frameshift assay for the BWYV pseudoknot in E. coli.

The BWYV RNA pseudoknot stimulates frameshifting in vitro in different eukaryotic systems, such as the rabbit reticulocyte lysate and in vivo in human embryonic kidney cells (Kim et al. 1999). The frameshifting efficiency is about $4 \%$ in eukaryotes (Kim et al. 1999; Cornish et al. 2005). However, in vivo in E. coli, frameshift efficiencies are reduced significantly $(0.8 \%)$ and proved mostly insensititive to structural disruption of the pseudoknot (Garcia et al. 1993). In order to use the BWYV pseudoknot as a model with $E$. coli ribosomes, it was therefore necessary to establish that the pseudoknot is able to promote -1FS in $E$. coli, and that sensitivity to pseudoknot structural changes can be restored. The ability of some eukaryotic mRNA frameshifting signals to promote $-1 \mathrm{FS}$ into the prokaryotic translational machinery has been demonstrated (Weiss et al. 1989; Brunelle et al. 1999), however, with an efficiency that can be lower (Brunelle et al. 1999; Plant and Dinman 2006). Here we show that it is necessary to shorten the spacer by 1 or 2 nucleotides (nt) in order to re-establish a BYYV pseudoknot-dependent -1FS mechanism in E. coli to a level comparable to the eukaryotic system. 
Subsequently, RNA chemical probing and footprinting analyses were used to characterize the interaction of the BWYV pseudoknot with E. coli ribosomes. We used two mRNA constructs. The first construct has the wild-type spacer sequence, but does not promote $-1 \mathrm{FS}$ in E. coli, whereas the second construct has -1 FS activity with a 1-nt shortened spacer. For both constructs, our chemical modification data reveal a compact overall conformation for the bound pseudoknot. Differences between RNA constructs were, however, observed in the region that contacts the ribosomal helicase center. The results provide a first visualization of the effects of a change in the reading frame in which the ribosome encounters the pseudoknot. Indeed, deletion of a single nucleotide in the spacer sequence results in the repositioning of the pseudoknot that is more engulfed in the mRNA entry site. In this configuration, the first base pair of stem 1 readily melts, placing the ribosome in the frameshifting-prone configuration where the following three base pairs that need to be unfolded may offer stronger resistance, since they are engaged in tertiary interactions with loop 2 nucleotides. This difference will likely influence the unfolding kinetics of the helical junction that is believed to strongly influence frameshifting (Cornish et al. 2006). Our results suggest that in some cases, the ground state of the pseudoknot may have already been altered prior to the EF-G catalyzed 30S translocation. In addition, the findings further support the hypothesis that tension may play a crucial role in $-1 F S$ mechanism.

\section{RESULTS}

\section{Frameshifting assays in E. coli}

Frameshifting was measured in vivo by using E. coli cells. A dual-reporter assay system was constructed to measure frameshifting efficiencies with a vector containing the glutathione $S$-transferase (GST) gene and the luciferase protein (Luc) downstream from the GST gene (Fig. 2). The slippery, spacer, and pseudoknot sequences were inserted between the GST and Luc open reading frames (construct BWYV). Our construct was designed such that translation into the $L u c$ gene is a monitor for ribosomal frameshifting: full-length, active luciferase will result only if ribosomes frameshift on the mRNA within the slippery sequence. If the ribosome does not shift frame, a stop codon downstream from the pseudoknot prevents synthesis of full length luciferase. Frameshift efficiencies were calculated as previously described with all frameshifting data normalized using a control construct $[(-1) \Delta \mathrm{PK}]$ expressing the GSTluciferase fusion protein to account for ribosome drop-off, etc. (Habig et al. 1974; Grentzmann et al. 1998). The GST activity of the fusion protein was identical to GST alone showing that the presence of luciferase at the C-terminus of the GST sequence does not affect GST activity (data not shown).

The mRNA construct containing the BWYV pseudoknot, with wild-type length spacer and slippery sequence, yielded $0.7 \%$ frameshifting efficiency in vivo (Fig. 3, BWYV), in agreement with previous results in E. coli (0.8\%) (Garcia et al. 1993). Frameshift efficiencies may be enhanced by substitution of the wild-type slippery sequence (GGGAAAC) by the heptanucleotide AAAAAAG sequence, which is known to substantially enhance frameshifting in E. coli (Weiss et al. 1989; Blinkowa and Walker 1990; Flower and McHenry 1990; Tsuchihashi and Kornberg 1990), and yields an increase of the frameshifting efficiency to $17 \%$ (Fig. 3, EC).

However, in order to restore frameshift efficiencies with the wild-type slippery sequence we decided to reduce the spacer length. Since the spacer is thought to be in an extended conformation and held at considerable tension when frameshifting occurs, the BWYV spacer may simply be too long for the smaller $E$. coli ribosomes, reducing tension and suppressing frameshifting (Brierley et al. 1989; Tsuchihashi and Kornberg 1990; Kim et al. 2001; Bertrand et al. 2002). Spacer shortening may therefore restore frameshift by increasing the level of tension above the threshold necessary for frameshifting, and/or by re-establishing optimal 


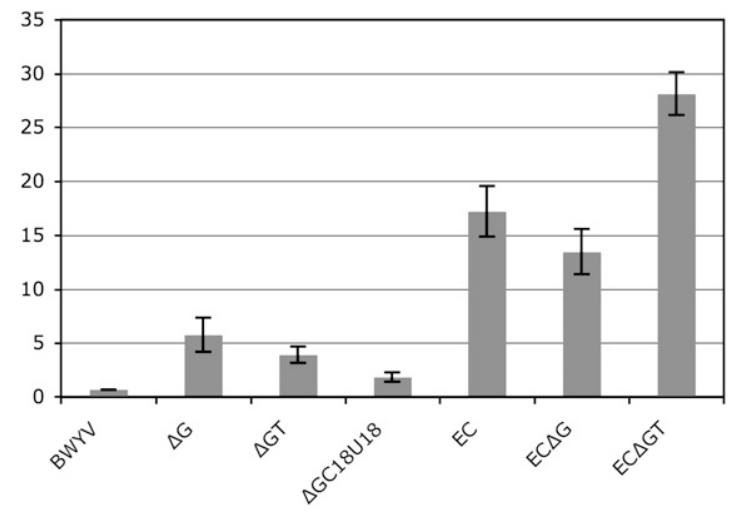

FIGURE 3. Frameshift efficiency obtained in vivo for various BWYV constructs. The frameshift efficiency was measured in E. coli by measurement of luciferase activities and adjusted by the GST activities of the cell extracts. The luciferase/GST activity is normalized as inframe and out-of-frame constructs to have $100 \%$ and $0 \%$ activity, respectively.

contacts between the ribosome and the pseudoknot. Deletions by 1 or 2 nt were made (Fig. 2B, constructs BWYV $\Delta \mathrm{G}, \mathrm{BWYV} \Delta \mathrm{GT})$. In order to keep constant the reading frame (downstream from the pseudoknot) one or two nucleotides were inserted downstream from the pseudoknot for $\Delta \mathrm{G}$ and $\Delta \mathrm{GT}$ mutants, respectively (Fig. 2B). Deletion of a $1 \mathrm{nt}$ (Fig. 3, mutant $\Delta \mathrm{G}$ ) or $2 \mathrm{nt}$ (Fig. 3, $\Delta \mathrm{GT}$ ) in the spacer sequence leads to mRNA sequences that show increased frameshifting efficiencies, 5.8\% and 3.9\%, respectively, compared with $0.7 \%$ obtained with the wild-type mRNA. Surprisingly, with the AAAAAAG slippery sequence, the frameshifting level was substantially increased for $\Delta \mathrm{GT}$ (28\%), whereas the $\Delta \mathrm{G}$ construct remained close to the construct with wild-type spacer (13.5\%) (Fig. 3).

In order to demonstrate that spacer shortening also restores sensitivity to mutation and is dependent upon the structure of the BWYV pseudoknot, a mutant where C18 is substituted to U18 was constructed in the $\Delta \mathrm{G}$ mRNA. This mutation has been shown to abolish -1FS in rabbit reticulocyte extracts (Kim et al. 1999). We observed that the mutation $\mathrm{C} 18$ to $\mathrm{U} 18$ also significantly reduces frameshifting in E. coli from $5.8 \%$ to $1.8 \%$ (Fig. 3).

\section{Conformation of the BWYV pseudoknot within a T4 gene 32 mRNA derivative}

In order to study the pseudoknot interaction with E. coli $70 S$ ribosomes, we introduced the slippery sequence, spacer, and BWYV frameshifting pseudoknot in a derivative of bacteriophage T4 gene 32 mRNA (Fig. 1). We first investigated the conformation of the pseudoknot within the gene 32-BWYV mRNA, in the absence of ribosomes, by chemical probing (Fig. 4A). Nucleotides that lie outside the region of the pseudoknot were found to be highly reactive to chemical probes in agreement with the absence of any stable secondary structure. On the contrary, the RNA sequence corresponding to the pseudoknot is structured as indicated by the nonreactivity or very weak reactivity to kethoxal or DMS of positions C13-G16, C20, C21, C24-G28, G37, and G38. We note a weak reactivity for nucleotides G17, C18, G22, and G38 that are involved (except C18) in terminal Watson-Crick base pairs in stems S1 and S2 (Fig. 4A,B). In loop 1, base A19 is modified by DMS in BWYV and $\Delta$ G-BWYV mRNAs (Fig. 4C). The uracil base $\mathrm{U} 23$ is found slightly reactive to CMCT (Fig. $4 \mathrm{~A})$. Overall, the chemical probing data of the RNA pseudoknot (Fig. 4B) shows the formation of the two stems S1 and S2. We further note a slight reactivity with DMS of nucleotides A30-C36 in the loop L2 at a temperature of $30^{\circ} \mathrm{C}$ close to physiological conditions.

In addition, nuclear magnetic resonance (NMR) spectroscopic data suggest that the overall conformation of the pseudoknot was not altered by the presence of $5^{\prime}$ and $3^{\prime}$ additional nucleotides within the mRNA sequence. NMR spectra of exchangeable protons were recorded in identical buffer conditions for a 27-nt BWYV pseudoknot construct (Fig. 1, sequence G12-G38) and a shorter version of the gene 32-BWYV mRNA (Supplemental Fig. S1). We identified the NMR signature of the protonated cytidine that has been previously identified in the core structure of the pseudoknot (Su et al. 1999; Nixon et al. 2002). Together, NMR and chemical probing data confirm that the pseudoknot can adopt its overall conformation in the context of the mRNA construct.

\section{Chemical probing of the wild-type BWYV pseudoknot bound to $E$. coli ribosome}

Subsequently, we probed the structure of the gene 32-BWYV mRNA bound to $70 \mathrm{~S}$ ribosome, $\mathrm{P}$-site and A-site tRNAs $\left(\mathrm{tRNA}^{\text {Gly }}\right.$ and $\mathrm{tRNA}^{\mathrm{Asn}}$ ) in a pretranslocation state with DMS and kethoxal. Binding of mRNA and deacylated tRNAs to the P- and A-sites that are active in translation were performed as previously described (Joseph and Noller 1998; Wilson and Nechifor 2004) except that ribosomes were ten times in excess in molar ratio compared to mRNA, in order to minimize the presence of unbound mRNA. tRNA $^{\text {Gly }}$ was bound to the P-site and paired with codon 1 (GGA) or possibly to the GGG codon in the -1 frame (Fig. $4 \mathrm{~B})$. tRNA ${ }^{\text {Asn }}$ was subsequently bound to the A-site to pair with codon 2 (AAC). The chemical modification patterns show that the mRNA interacts with the ribosome (Fig. 4A) as indicated by the strong protection of the bases $A(-13)$, $A(-12), G(-11)$, and $G(-10)$ of the Shine-Dalgarno sequence (Huttenhofer and Noller 1994). Bases $G(-1), A(-2)$, and $\mathrm{A}(-3)$ that correspond to the E-site codon are also protected from DMS and kethoxal attack. Bases $\mathrm{G}+1, \mathrm{G}+2$, $\mathrm{A}+3, \mathrm{~A}+4, \mathrm{~A}+5$, and $\mathrm{C}+6$ of glycine and asparagine codons are protected from chemical modifications demonstrating Watson-Crick pairing with the anticodons of $\mathrm{tRNA}^{\text {Gly }}$ and tRNA $^{\text {Asn }}$. 
A

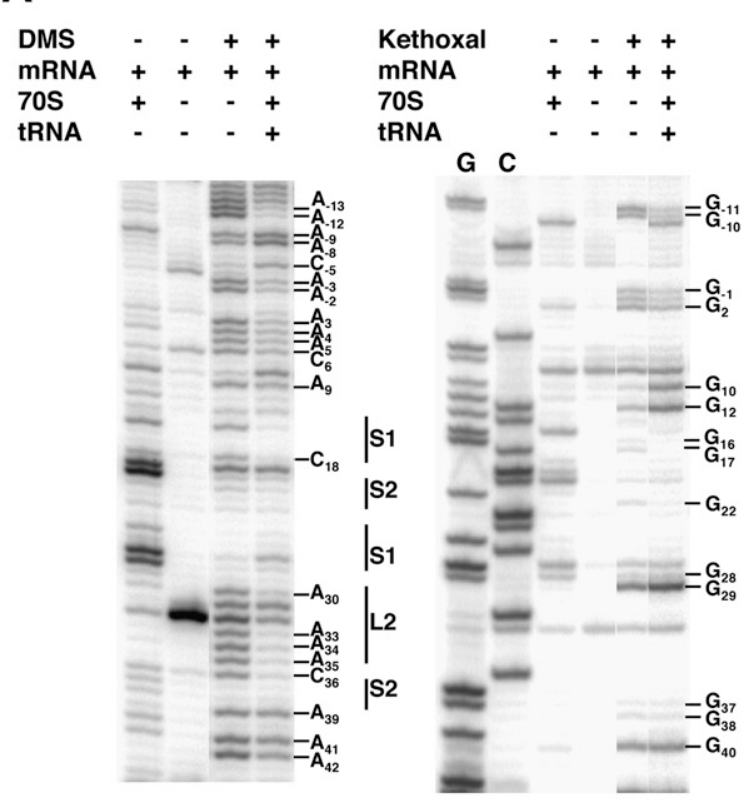

C

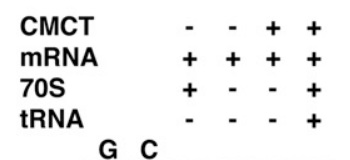
G C

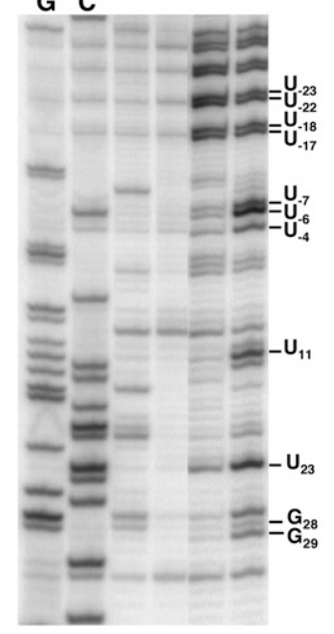

B

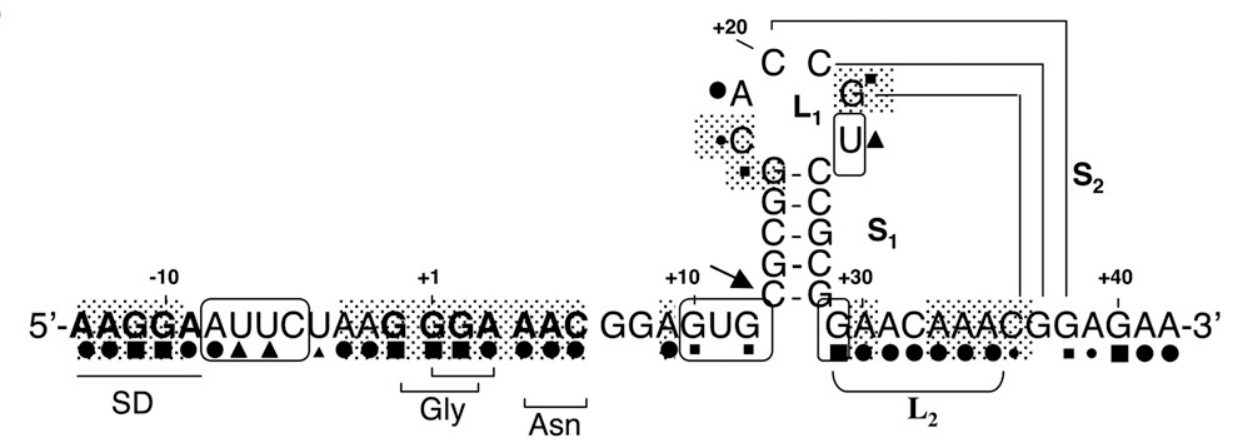

FIGURE 4. (A) Chemical probing of mRNA-BWYV free or complexed with 70S, tRNA ${ }^{\text {Gly }}$, and tRNA ${ }^{\text {Asn }}$ analyzed by primer extension. Left panel: DMS; middle panel: kethoxal; right panel: CMCT. G, C, dideoxy sequencing lanes are shown on the left part of the gel. In each panel, all lanes were extracted from a single gel. $(B)$ Sites reactive to chemical probes in the free mRNA are depicted on the secondary structure model. Filled circles: DMS, squares: kethoxal, triangles: CMCT, the different degrees of nucleotide accessibility are indicated by the sizes of the symbols. The footprint protections observed upon binding of the ribosome are shaded. The nucleotides with increased reactivity are encircled. The arrow indicates the increase of reactivity of nucleotide $\mathrm{C} 13$ in the $\Delta \mathrm{G}$ mRNA-ribosome complex. Glycine and asparagine codons are indicated. (C) Chemical probing with DMS of the $\Delta \mathrm{G}$ mRNA-BWYV construct free or complexed with 70S, tRNA ${ }^{\text {Gly }}$, and tRNA ${ }^{\text {Asn }}$. For clarity, the same numbering was kept for the nucleotides downstream from the deleted $\mathrm{G}$ nucleotide.

We further note the protection from DMS modification of nucleotide $\mathrm{A}+9$ in the spacer region. A striking change in the modification pattern of the pseudoknot is seen with the decrease of accessibility to DMS at A+30, A+33, A+34, $\mathrm{A}+35$, and $\mathrm{C}+36$. This change is accompanied by a small decrease of reactivity of nucleotides G17 and G22 located at the edges of stems S1 and S2, as well as for nucleotide $\mathrm{C} 18$ in loop 1. Finally, we observed strong increase of the reactivity of bases $\mathrm{G}+10, \mathrm{U}+11$, and $\mathrm{G}+12$ with also an increase to a weaker extent of base G+29.

Since the presence of the pseudoknot may interfere with the positioning of the mRNA in the mRNA track downstream from the A-site codon (Huttenhofer and Noller 1994), we investigated this possibility using the toeprinting assay (Hartz et al. 1989). The correct location of the pseudoknot at the mRNA entrance is supported by the observation of a strong +15 toeprint signal in the presence of ribosome and tRNA (Supplemental Fig. S2). The +15 toeprint is a hard stop (independent of the reverse transcription activity), indicating that the mRNA secondary structure unfolds during cDNA synthesis as previously seen for a stem-loop (Ringquist et al. 1993) or a pseudoknot (Philippe et al. 1993).

\section{Chemical probing of the $\Delta G$ frameshifting mRNA bound to $E$. coli ribosome}

Ribosome-mRNA-tRNA complexes in the pretranslocation state using the frameshifting gene $32-\Delta \mathrm{G}-\mathrm{BWYV}$ mRNA were formed under identical conditions as for the wild-type 
gene 32-BWYV mRNA. The deletion of the spacer nucleotide G10 now places stem 1 between positions +11 and +12 . For easy comparison with the wild-type mRNA data, the numbering of nucleotides for the gene $32-\Delta \mathrm{G}-\mathrm{BWYV}$ mRNA (downstream from the deleted G10) was kept identical to the wild-type sequence. The level of reactivity of loop 2 nucleotides was investigated by modification of the mRNA bound to ribosome with DMS (Fig. 4C). The modification pattern in the frameshifting pseudoknot is very similar to that obtained with the wild-type mRNA in the $5^{\prime}$ region (Shine-Dalgarno sequence, codons glycine, and asparagine). Adenines A30, A33, A34, and A35 and residue $\mathrm{C} 36$ in the pseudoknot showed somewhat reduced reactivity to DMS in the presence of the ribosome. However, the most prominent and most interesting difference is the increased reactivity of nucleotide C13 in the first base pair of stem 1 in $\Delta \mathrm{G}$ mRNA.

Since our experiments are in the absence of EF-G, essentially off-pathway states are probed. To also study the pseudoknot structure "on pathway," in the presence of EF-G, we confirmed the formation of stalled ribosome complexes in vitro using a toeprinting assay (Supplemental Fig. S2). In addition to the strong +15 toeprint signal already described above, we detected, in the presence of A- and P-site bound tRNAs, a weaker toeprint (position +29) probably resulting from a stop of reverse transcriptase at the first base pair of stem 1 (Supplemental Fig. S2; Philippe et al. 1993; Spedding et al. 1993). After attempted EF-G catalyzed translocation of $\mathrm{tRNA}^{\text {Leu }}$ to the P-site, this toeprint signal became slightly stronger with only the appearance of an additional very weak signal at the expected position +19 . This shows that, in vitro, the presence of the pseudoknot seriously impairs translocation. Any further addition of excess $\mathrm{tRNA}^{\text {Gly }}$ or $\mathrm{tRNA}^{\text {Lys }}$ did not further stimulate movement of the ribosome downstream. Only a weak toeprint at the expected position +22 for the next translocation step (tRNA ${ }^{\text {Gly }}$ ) was observed. We noticed a decrease of the signal at +15 in the presence of EF-G, which can be explain partially by the increase of frequency of reverse transcriptase stops at the downstream position +29 . We then investigated stalled ribosome-mRNA-tRNA-EF-G complex using chemical probing, but we could not obtain clean data.

\section{Decrease in the reactivity of loop 2 nucleotides is ribosome dependent}

Misfolding and aggregation of RNA constructs of the BWYV pseudoknot have previously been reported (Cornish et al. 2005). It is therefore possible that the observed protection of loop 2 nucleotides upon ribosome binding would be the result of misfolding of the free pseudoknot due to the presence of $5^{\prime}$ and $3^{\prime}$ surrounding nucleotides. In this case, loop 2 nucleotides in a misfolded pseudoknot may be reactive to chemical probes and binding of the ribosome would drive proper folding of the RNA by sequestering the $5^{\prime}$ single-stranded region inside the ribosome. In order to rule out this possibility we performed a chemical probing experiment in the same experimental conditions except that the ribosome and tRNAs were substituted by a DNA oligonucleotide that hybridized to the $5^{\prime}$ region normally buried inside the ribosome in the 70S-mRNA-tRNA complexes (Fig. 5A). In presence of five and 10 times excess of DNA we observed a pause of the reverse transcriptase created by the presence of the $3^{\prime}$ end of the DNA bound to the RNA (Fig. 5B). The protection of nucleotides A-9 and A-3 (Fig. 5B) at the DNA binding site is also observed. These signals demonstrate correct hybridization of the DNA oligonucleotide. DNA binding had no effect in the reactivity of loop 2 nucleotides of the pseudoknot, indicating that the observed decrease in reactivity of loop 2 nucleotides within the ribosome-bound pseudoknot is a direct consequence of the presence of the ribosome.

\section{DISCUSSION}

We have shown that -1 BWYV frameshifting efficiencies can be restored to eukaryotic levels using the wild-type slippery sequence (GGGAAAC) with E. coli ribosomes, provided the spacer is shortened. A deletion of a single nucleotide within the spacer not only restored frameshifting efficiencies, but more importantly, also re-established sensitivity to pseudoknot structural integrity. One possible interpretation of such a result is that the modified reading frame in which the ribosome encounters the pseudoknot has altered the interaction with the ribosome, consequently restoring -1 frameshifting. It remains of interest for future work to investigate if a simple 1-nt shortening of the spacer also restores kinetic parameters (pausing, mRNA unfolding) (Kontos et al. 2001; Chen et al. 2007; Hansen et al. 2007; Green et al. 2008), or if -1 frameshifting may have been restored by a different mechanism altogether. On the other hand, our result also appears qualitatively in agreement with frameshifting models that rely upon the buildup of tension (or torsional strain) when ribosomes encounters a folded pseudoknot (Plant and Dinman 2005). Possible effects of such tension have recently been visualized by cryoelectron microscopy in the case of eukaryotic ribosomes, where translocation by eIF2 induced tension in the mRNA that bends the P-site bound tRNA in the $3^{\prime}$ direction (Namy et al. 2006). Hypervariable expansion segments in rRNA account for substantial conformational differences between eukaryotic and prokaryotic ribosomes, essentially extending the length of the eukaryotic mRNA tunnel as such a segment protrudes from the surface of the mRNA entrance site in the canine $40 \mathrm{~S}$ ribosomal subunit (Chandramouli et al. 2008). For a given spacer length one expects the mRNA to be at higher tension when extended in the eukaryotic tunnel than in the slightly shorter prokaryotic mRNA tunnel. Thus, smaller E. coli ribosomes (Spahn et al. 
A

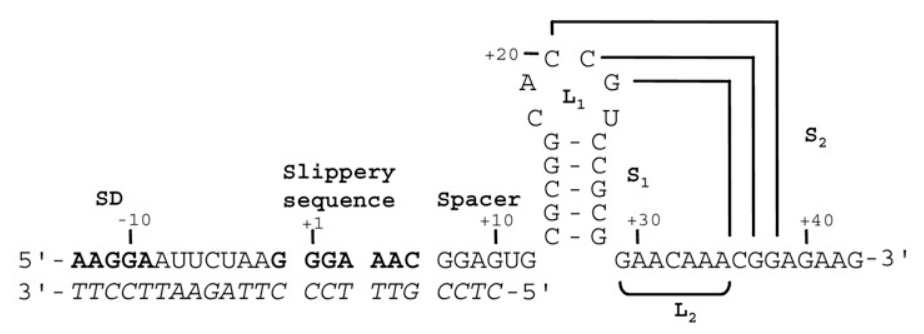

B

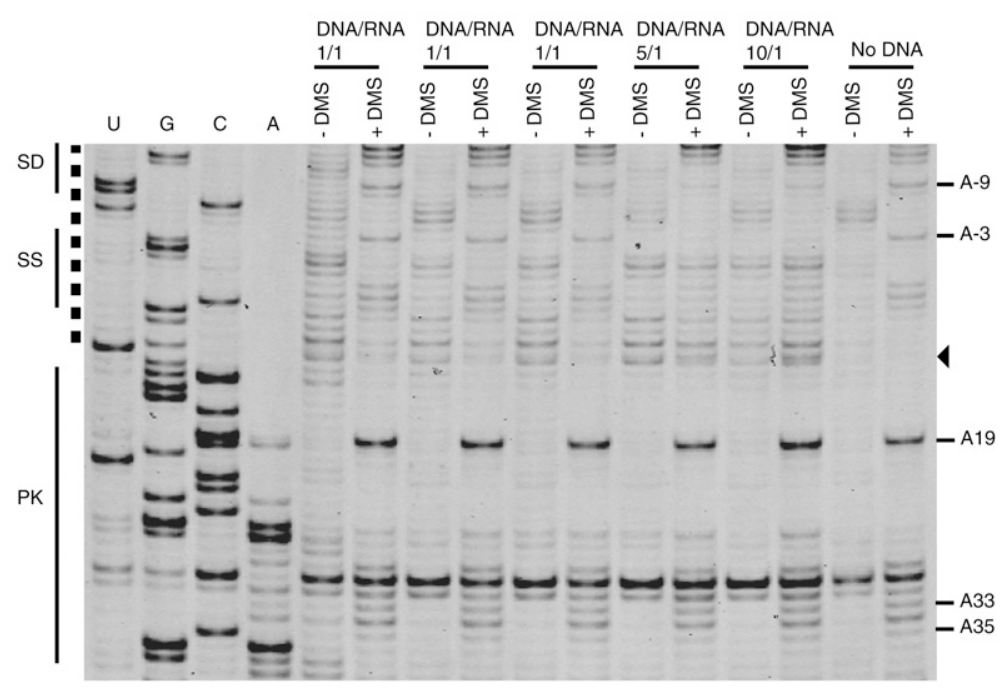

FIGURE 5. Footprint experiment with a DNA oligonucleotide mimicking ribosome binding. (A) Secondary structure of the BWYV mRNA. The hybridized DNA oligonucleotide sequence is in italics. (B) Footprinting experiment visualized by PAGE with IRD-700. Structural elements from BWYV mRNA are shown on the left, SD: Shine-Dalgarno, SS: slippery sequence, PK: pseudoknot. A dashed line shows the region of the mRNA expected to hybridize to the DNA oligonucleotide. Three ratios of DNA/RNA were tested 1/1,5/1, and 10/1. Nucleotides A-8 and A-9 that are protected by DNA binding are indicated on the right by a line. No footprint is observed in loop 2 region (A33-A35). Nucleotides were identified by comparison with the dideoxy sequencing reactions (lanes $U, G, C, A$ ). An arrow indicates nucleotides corresponding to a pause of the reverse transcriptase due to the presence of the DNA oligonucleotide.

2001) may decrease frameshift efficiency due to a concomitant reduction in tension, and therefore shortening of the spacer is expected to restore tension and frameshift efficiencies.

Interestingly, when the wild-type slippery sequence is replaced with the AAAAAAG sequence, which was to increase frameshift efficiencies in $E$. coli, we found that only the 2-nt shortened spacer restored frameshift efficiencies, which seems inconsistent with the simple tension hypothesis. Why would $\Delta \mathrm{G}$ deletion not increase frameshift efficiency as it did with the wild-type slippery sequence? The development of tension in the spacer, however, is likely to rely not only upon downstream deformations near the ribosome entrance site, but also upon local deformations at the coding, A- and P-sites (Namy et al. 2006). It is conceivable that the AAA codon replacing the GGG codon, allows for increased deformation, thus relieving some of the tension, not sufficient however, to relieve the even further elevated tension when a 2-nt shortened spacer is used. We note that the observed increase in frameshift efficiencies using the AAAAAAG slippery sequence exceed those previously reported (Garcia et al. 1993), the reason for which may reside in the mutation made in the spacer sequence in this previous work.

Before investigating the BWYV structure in the presence of bound ribosomes, we confirmed appropriate folding of the BWYV PK within the T4 gene 32 mRNA derivative using the chemical probing approach. Segments C13-G17, C20-G22, C24-G28, and C36-G38 were shown to display weak to zero reactivity with DMS or kethoxal, which is consistent with their interaction to form the base-paired stems S1 and S2 of the pseudoknot. Nucleotides A19, U23, and G29, which are bulged in the structure of the pseudoknot, are found highly reactive to DMS, CMCT, and ketoxal, respectively. Adenines from the segment A30-A35 in loop 2 and residue C36 in stem 2 showed moderate reactivity to DMS, suggesting flexibility in this region of the RNA. This is in agreement with the fact that the segment A31-C36 has the highest $B$ factor values (with the 5 '-end nucleotide) in the crystal structure of the BWYV pseudoknot ( $\mathrm{Su}$ et al. 1999), which is indicative of high flexibility. Interestingly, we note that nucleotide A30, which has low B factor values in the crystal structure, has a moderate reactivity to DMS, suggesting some flexibility in solution. We conclude that observed reactivities are consistent with the known structure and that the pseudoknot folds correctly within the $\mathrm{T} 4$ gene $32 \mathrm{mRNA}$ derivative.

The effect of ribosomes bound at the slippery sequence upon the downstream pseudoknot structure was then studied. Unexpectedly, we did not observe any significant differences in reactivity patterns between the nonframeshifting and frameshifting $\Delta \mathrm{G}$ pseudoknot, except for base C13, which showed increased reactivity in the $\Delta \mathrm{G}$ mutant (see below). We started this investigation with the wildtype mRNA pseudoknot construct for which stem 1 is between positions +12 and +13 . Protection at the ShineDalgarno sequence, and the $\mathrm{P}$ - and A-site codons was clearly observed, in agreement with previous observations for unstructured mRNA (Huttenhofer and Noller 1994), 
which together with the toeprinting data, indicates that the mRNA was correctly positioned in the ribosome. It has previously been reported that P-site tRNA binding protects the nucleotide in position -1 (Huttenhofer and Noller 1994). However, in our case, in addition to G-1, A-2, and A-3 are also protected. These nucleotides correspond to the E-site codon. The most straightforward interpretation of this protection would be codon-anticodon pairing at the E-site. This observation is consistent with recent crystallographic data, where the E-site codon is in a relaxed conformation with a classical A-helical geometry compatible with Watson-Crick pairing with the E-site tRNA anticodon (Jenner et al. 2007). However, for A-2, we cannot rule out the possibility that tRNA ${ }^{\text {Gly }}$ binding in the -1 frame at the slippery sequence, generated a protection similarly to the observation of Huttenhofer and Noller (1994) for the -1 position.

In the spacer region we observed weak protection from DMS modification of adenine at position +9 , consistent with its position inside the mRNA tunnel (Yusupova et al. 2001). Position +11 has been identified as the limit of accessibility of a RNA double helix at the mRNA entrance (Takyar et al. 2005). Our chemical probing data show for BWYV mRNA, an increase in the reactivity for bases G10 and G12 at the $3^{\prime}$ end of the spacer, and for the first nucleotide of loop 2, G29. These nucleotides lie on the same face in the structure of the pseudoknot. One attractive explanation to this increase of reactivity of these nucleotides is that they may be the result of contacts with the ribosomal helicase center that modify their conformation.

The effect of proximity of the ribosomal surface on the pseudoknot structure is not restricted to the region that is first "hit" by the ribosome. Strong protection was seen for some of loop 2 nucleotides A30, A33, A34, and A35. This effect is selective as the reactivity of nucleotide A31 was not affected by binding of the ribosome. All the $\mathrm{N} 1$ positions of these adenine residues are engaged in tertiary contacts in the pseudoknot structure except A31 whose N1 position is accessible to solvent (Su et al. 1999). This, together with the weak footprints in the core region of the pseudoknot, as well as the increase in reactivity of the extruded nucleotide U23, point toward a compact and rather stable RNA pseudoknot structure that is in a confined environment at the mRNA entry site. Based on toeprinting analysis, stabilization of pseudoknot structures by the ribosome has been previously proposed for mRNAs involved in translational regulation (Philippe et al. 1993; Spedding et al. 1993). Here, this finding for the wild-type pseudoknot is shared with the $\Delta \mathrm{G}$ mutant, since only minor differences in reactivities and footprints were observed. This suggests that the observed difference in frameshift efficiency may not be the consequence of any altered contacts between ribosome and pseudoknot in the pretranslocation complex probed here. Docking of several pseudoknots to the structure of the 30 S subunit have illustrated how nucleotides protruding out of the pseudoknot structure are available to establish contacts with the ribosomal surface (Giedroc et al. 2000; Plant et al. 2003; Pallan et al. 2005). These nucleotides are not engaged in secondary or tertiary interactions and their substitution by other nucleotides lead mostly to weak effects on $-1 F S$ efficiencies (Kim et al. 1999). However, in some instances, direct contacts of certain nucleotides with the ribosome were proposed to explain the variation of $-1 F S$ efficiencies. This is the case for nucleotide G29, since it lies on the face approached by the ribosome and a G29U mutation lead to $30 \%$ increase in the level of $-1 F S$ and insertion of a C following U29 increased -1 FS by threefold (Kim et al. 1999). It is not known when these contacts would be established, i.e., in the pretranslocation state or in complexes "on pathway" in the presence of EF-G during translocation. In our study, in the pretranslocation complexes, none of the bulged nucleotides A19, U23, and G29 were protected by the ribosome, suggesting that the prokaryotic ribosome does not establish, at this stage, strong and stable interaction with the Watson-Crick face of these bases. However the strong increase in the reactivity of G29 to kethoxal indicates that the mRNA entrance environment does influence the conformation of this region of the pseudoknot.

Our findings leave the possibility that conformational changes upon binding of EF-G may differentially affect ribosome-pseudoknot contacts, and account for altered frameshift efficiencies (Frank and Agrawal 2000; Valle et al. 2003; Wilson and Nechifor 2004; Spiegel et al. 2007). To address this issue, we have attempted stalling and probing on-pathway ribosomes. Toeprinting assay showed that the presence of the downstream pseudoknot seriously impairs translocation by the ribosome leading to stalled ribosomal complexes. Unfortunately, so far, we have been unsuccessful in obtaining clear chemical probing data on these stalled tRNA-mRNA-ribosome complexes, which will be the subject of future investigations.

Interestingly, in the absence of EF-G, the most prominent difference observed with the $\Delta \mathrm{G}$ mutant (the 1-nt shortened spacer) is that the increase of reactivity extends further downstream to nucleotide $\mathrm{C} 13$, the first base pair of stem 1. The melting of this base pair is likely a direct consequence of the shorter spacer, which now places stem 1 inside the helicase center. This is the first direct visualization of the consequences of a shorter spacer on the conformation of the PK bound to ribosome. An increase of reactivity of this base moiety agrees with the hypothesis that basic side chains protruding from ribosomal proteins S3, S4, and S5 at the helicase center contact phosphate groups of the RNA in a sequence independent manner (Takyar et al. 2005).

Here we have shown that it is necessary to shorten the spacer sequence in order to restore efficient $-1 F S$ and sensitivity to pseudoknot structural integrity (C18U mutant) with E. coli ribosomes. The consequences of such a shorter 
spacer on the positioning and conformation of the pseudoknot at the mRNA entry site were previously unknown. One would expect, in this configuration, the pseudoknot to be closer to the ribosomal surface when the slippery sequence is bound at the A- and P-sites. Contacts between the ribosome and pseudoknot in the pretranslocation state were observed as decreases in reactivity. The fact that we did not observe any substantial differences in reactivity between the wild-type and $\Delta G$ pseudoknot indicates that both constructs contact the ribosome identically, except for partial unfolding of the $\Delta G$ pseudoknot (C13) near the helicase center of the ribosome. This last observation shows that the $\Delta \mathrm{G}$ pseudoknot is indeed closer and more engaged in the helicase center than the wild-type pseudoknot in the pretranslocation state and that this is one configuration that may possibly lead to frameshifting. It implies that the three base pairs in stem 1, which will need to be melted during the translocation step, differ between the frameshifting and nonframeshifting pseudoknots. Thus, the ribosome will approach the functionally important helical junction (Cornish et al. 2006) differently, which is likely to influence unfolding kinetics. In the nonframeshifting construct, the C13-G28, G14-C27, and C15-G26 pairs would have to be melted. In the frameshifting construct, the first base pair of stem 1 (C13-G28) that passively melts is not involved in the triplex with L2 nucleotides (Su et al. 1999). On the contrary, the three following pairs, G14-C27, C15-G26, and G16-C25, are engaged in tertiary interactions with loop 2 nucleotides and may therefore offer more resistance to unfolding. On the other hand, it remains possible that optimal contacts between the ribosome helicase (if required) and the structure to unwind are altered for the $\Delta G$ pseudoknot. As discussed above, the mechanism by which $-1 F S$ is here restored is likely to involve EF-G induced alterations, which remain to be clarified by future experiments. The work presented here provides the necessary background for such experiments. In general, studying the different ways that ribosomes, in different stages of the translation-elongation cycle (e.g., pretranslocation), may differentially act on the conformation of frameshifting and nonframeshifting pseudoknots is expected to provide an improved understanding of why structurally similar pseudoknots have such a wide range of frameshifting efficiencies.

\section{MATERIALS AND METHODS}

\section{Construction of templates for frameshifting assay}

The glutathione S-transferase (GST) gene was PCR-amplified from pGEX2T vector (Amersham Biosciences) and inserted between the NdeI and NcoI sites of pET29b vector (Novagene). Luciferase gene was amplified from the pBESTluc vector (Promega) by PCR and cloned downstream from the GST gene in between BamHI and HindIII sites (pGST-Luc). Synthesized oligonucleotide CCATGGTCAGGTACCGGATCC were inserted in-between GST and luciferase genes (NcoI/BamHI sites) to obtain pGST-
UCA-Luc, resulting in the creation of an additional KpnI cloning sites in-between these restriction sites. Finally, BWYV frameshifting signal was PCR amplified from plasmid mpk-BWYV (see below) and cloned into NcoI and KpnI sites of pGST-UCA-Luc (pGST-BWYV-Luc). Control plasmids, $(-1) \Delta \mathrm{PK}$ and $\Delta \mathrm{PK}$ were obtained from the by-products of the cloning. Plasmids bearing mutations in the slippery sequence and/or the spacer sequence were constructed by introducing DNA duplex that were PCR amplified from NcoI-KpnI region of pGST-BWYV-Luc using primers containing corresponding mutations and cloned into the same region of pGST-UCA-Luc.

The resulting plasmid pGST-BWYV-Luc contains a UAA termination codon 29 amino acids downstream from the GST gene. If $a-1$ frameshift occurs at the slippery sequence, the termination codon is not read and translation proceeds to the luciferase gene, resulting in the production of a GST-luciferase protein with 22 amino acid linker.

\section{Frameshifting assay}

For the in vivo assay reporter plasmids were transformed in E. coli BL21(DE3) strain. Cells were grown at $37^{\circ} \mathrm{C}$ in $1.5 \mathrm{~mL}$ of Luria Broth with $50 \mathrm{mg} / \mathrm{L}$ of kanamycin. The reporter protein expression was induced at $A_{600}=0.6$ by the addition of $100 \mu \mathrm{M}$ isopropyl- $\beta$-D-thiogalactopyranoside (IPTG) and cells were harvested after $3 \mathrm{~h}$ of growth. The cells were suspended in $400 \mu \mathrm{L}$ of MTPBS (150 mM NaCl, $16 \mathrm{mM} \mathrm{Na}_{2} \mathrm{HPO}_{4}, 4 \mathrm{mM} \mathrm{NaH}{ }_{2} \mathrm{PO}_{4}$ at $\mathrm{pH}$ 7.3) and lysed by sonication. The lysate was centrifuged at $10,000 \mathrm{~g}$ for $10 \mathrm{~min}$ at $4^{\circ} \mathrm{C}$ and supernatant was used for the frameshifting assays.

GST activity was measured by mixing $10 \mu \mathrm{L}$ of cell extract with $200 \mu \mathrm{L}$ of $100 \mathrm{mM}$ potassium phosphate buffer at $\mathrm{pH} 6.5$ containing $0.5 \mathrm{mM}$ 1-chloro-2,4-dinitrobenzene (CDNB) and $0.5 \mathrm{mM}$ reduced glutathione. For the in vitro synthesized product, $8 \mu \mathrm{L}$ of the translation reaction were mixed with $200 \mu \mathrm{L}$ of $100 \mathrm{mM}$ potassium phosphate buffer at $\mathrm{pH} 6.5$ containing $1 \mathrm{mM}$ CDNB and $1 \mathrm{mM}$ reduced glutathione. Absorbance at $340 \mathrm{~nm}$ of the mixture was measured for $10 \mathrm{~min}$ at $30 \mathrm{sec}$ intervals. The results were plotted to verify that the reaction rate is linear over the time and the GST activity was obtained from the $\Delta A_{340} / \mathrm{min}$ value. Luciferase activity was measured using a Luciferase assay system (Promega). For in vivo experiments 5-50 $\mu \mathrm{L}$ of cell extract were mixed with $50 \mu \mathrm{L}$ of $1 \mathrm{X}$ cell reporter lysis buffer and $50 \mu \mathrm{L}$ of luciferase assay reagent. The light produced was measured by Wallac Victor2 1420 multilabel counter (Perkin Elmer). Frameshifting efficiencies were calculated with the formula (Luc/GST)/ $\left(\operatorname{Luc}_{(-1) \Delta \mathrm{PK}} / \mathrm{GST}_{(-1) \Delta \mathrm{PK}}\right)$, where Luc and GST are the luciferase and GST activities, and $\operatorname{Luc}_{(-1) \Delta \mathrm{PK}}$ and $\mathrm{GST}_{(-1) \Delta \mathrm{PK}}$ are the activities for the control construct (Grentzmann et al. 1998). Experiments were performed in triplicate and associated error was reported as one standard deviation from the mean.

\section{Messenger RNA preparation}

A derivative of the phage T4 gene 32 mRNA (gene 32-BWYV) was prepared by in vitro transcription. Plasmid pUC118 containing a region of phage $\mathrm{T} 4$ gene 32 from nucleotide position -54 to +84 (where +1 is the translational start) downstream from an engineered phage T7 promoter sequence was used. The synthetic gene containing the BWYV pseudoknot was constructed by shotgun ligation of eight DNA fragments (25-31 mers) covering both 
strands and ligated in KpnI and BamHI sites. The gene $32 \Delta \mathrm{G}$ BWYV and $\triangle$ GT-BWYV constructs were obtained from the wild-type sequence (gene 32-BWYV) using the QuickChange site-directed mutagenesis kit (Stratagene). The transcripts were obtained by in vitro transcription of the synthetic genes flanked upstream by T7 RNA polymerase promoter region and downstream by a BamHI restriction site. Transcripts were purified by denaturing PAGE. Sequences of mRNAs were verified by sequencing with reverse transcriptase.

\section{Formation of 70S-mRNA-tRNA complexes}

Tight-couple 70S ribosomes from E. coli MRE600 were prepared as described in Powers and Noller (1991). Binding of mRNA was performed by incubating $480 \mathrm{pmol}$ of $70 \mathrm{~S}$ ribosome with $50 \mathrm{pmol}$ mRNA in $50 \mu \mathrm{L}$ buffer A ( $80 \mathrm{mM}$ potassium cacodylate at $\mathrm{pH} 7.2$, $150 \mathrm{mM} \mathrm{NH}_{4} \mathrm{Cl}, 1 \mathrm{mM} \mathrm{DTT}, 10 \mathrm{mM} \mathrm{MgCl}_{2}$ ), at $37^{\circ} \mathrm{C}$ for $10 \mathrm{~min}$. Next, 240 pmol of tRNA ${ }^{\text {Gly }}$ were added to fill the P-site by incubation at $37^{\circ} \mathrm{C}$ for $10 \mathrm{~min}$, and $240 \mathrm{pmol}$ of $\mathrm{tRNA}^{\mathrm{Asn}}$ were then added and incubated for $10 \mathrm{~min}$ to fill the A-site. mRNAtRNA-ribosome complexes were separated from free mRNA by successive steps of dilution and concentration with microcon. Fifty microliters of buffer $\mathrm{A}$ is added to $50 \mu \mathrm{L}$ of the complex and concentrated in microcon (YM-100). This step was repeated three times. Fifty microliters were recovered and diluted with $200 \mu \mathrm{L}$ of buffer $\mathrm{A}$ and distributed into $50 \mu \mathrm{l}$ aliquots on which modification will be performed.

\section{Messenger RNA translocation}

Histidine-tagged EF-G elongation factor was overexpressed in $E$. coli BL21 (DE3) and purified from the soluble extract on a $\mathrm{Ni}^{2+}$ agarose column as previously described (Wilson and Nechifor 2004). Messenger RNA translocation was assayed by toeprinting as described in Hartz et al. (1988) and Yoshizawa et al. (1999). Messenger mRNA $(1 \mu \mathrm{M})$ was annealed to a primer $(2 \mu \mathrm{M})$ in $50 \mathrm{mM} \mathrm{K}$-Hepes ( $\mathrm{pH} \mathrm{7.0)}$ ) and $100 \mathrm{mM} \mathrm{KCl}$ by heating to $90^{\circ} \mathrm{C}$ for $1 \mathrm{~min}$, and placed at room temperature until the temperature reached $45^{\circ} \mathrm{C}$. To form the complexes, tight-couple ribosomes (2$5 \mu \mathrm{M}$ ) (Powers and Noller 1991) from E. coli MRE600 were added to $0.6 \mu \mathrm{M}$ of mRNA in $60 \mathrm{mM} \mathrm{NH} 4 \mathrm{Cl}, 10 \mathrm{mM}$ Tris-acetate $(\mathrm{pH}$ 7.4), $20 \mathrm{mM} \mathrm{MgCl}_{2}$, and incubated at $37^{\circ} \mathrm{C}$ for $10 \mathrm{~min}$. tRNA $(4 \mu \mathrm{M})$ was added to fill the P-site by incubation at $37^{\circ} \mathrm{C}$ for 10 min and aliquot (0.6 pmol mRNA) was removed to ice for later extension. A second tRNA $(4 \mu \mathrm{M})$ was added to fill the A-site by incubation at $37^{\circ} \mathrm{C}$ for $10 \mathrm{~min}$ and aliquot ( $\left.0.6 \mathrm{pmol} \mathrm{mRNA}\right)$ was removed to ice for later extension. EF-G was added in buffer (50 $\mathrm{mM}$ Tris- $\mathrm{HCl}$ [pH 7.6], $20 \mathrm{mM} \mathrm{MgCl}_{2}, 100 \mathrm{mM} \mathrm{NH}_{4} \mathrm{Cl}, 1 \mathrm{mM}$ DTT, $1.5 \mathrm{mM}$ GTP), such that the final concentrations of GTP and EF-G were 300 and $1 \mu \mathrm{M}$, respectively. Reactions were incubated at $37^{\circ} \mathrm{C}$ for $10 \mathrm{~min}$, and aliquot (0.6 pmol mRNA) was removed from each reaction lacking or containing EF-G. Each aliquot was then extended in parallel (Stern et al. 1988) with $\left(5^{\prime}\right.$-CTTTATCTTCAGAAGAAAAACC- $\left.3^{\prime}\right)$ primer, and the products were resolved by $8 \%$ denaturing PAGE.

\section{Chemical probing of the RNA structure}

Samples $(50 \mathrm{pmol})$ of mRNA were folded in $20 \mu \mathrm{L}$ of buffer A (lacking $10 \mathrm{mM}$ magnesium) by warming at $95^{\circ} \mathrm{C}$ for $1 \mathrm{~min}$ followed by incubation at $4^{\circ} \mathrm{C}$ for $10 \mathrm{~min}$. The magnesium concentration was then adjusted to $10 \mathrm{mM}$. Chemical probing of mRNA-ribosome complexes (Yoshizawa et al. 1999) or free mRNA was performed by the addition of $4 \mu \mathrm{L}$ DMS (1:10 dilution in $95 \%$ ethanol), $8 \mu \mathrm{L} \mathrm{KE}\left(19 \mathrm{mg} / \mathrm{mL}\right.$ in $\left.\mathrm{H}_{2} \mathrm{O}\right)$, and $10 \mu \mathrm{L}$ CMCT ( $84 \mathrm{mg} / \mathrm{mL}$ in $\mathrm{H}_{2} \mathrm{O}$ ) to $50 \mu \mathrm{L}$ reaction mixture (see above). After incubation at $30^{\circ} \mathrm{C}$ for $10 \mathrm{~min}$ (for DMS and $\mathrm{KE}$ ) and at $37^{\circ} \mathrm{C}$ for $10 \mathrm{~min}$ (for CMCT), reactions were stopped and RNA was recovered as described. Sites of modification were analyzed by primer extension. All modification reactions were stopped by addition of $150 \mu \mathrm{L}$ of $95 \%$ (v/v) ethanol and $5 \mu \mathrm{L}$ of $3 \mathrm{M}$ sodium acetate followed by rapid mixing. The kethoxal-modified samples were adjusted to $25 \mathrm{mM}$ potassium borate ( $\mathrm{pH}$ 7.0). Pellets were resuspended in either $10 \mu \mathrm{L}$ of $\mathrm{H}_{2} \mathrm{O}$ (for DMS samples) or in $10 \mu \mathrm{L}$ of $25 \mathrm{mM}$ potassium borate (for kethoxal-treated samples). Cleaved fragments were separated on $7 \mathrm{M}$ urea/8\% (w/v) polyacrylamide gel, and quantified using a PhosphorImager.

\section{Fluorescent primer extension}

The fluorescent primer extension (FPE) methodology was used as previously described (Ying et al. 2007). IRD-700 fluorescent DNA primer was purchased from MWG Biotech. Modified mRNA $(2.5 \mu \mathrm{L}, 0.6 \mathrm{pmol})$ was added to fluorescent reverse transcription primer $(10 \mathrm{pmol})$ in hybridization buffer $(25 \mathrm{mM}$ Hepes- $\mathrm{KOH}$ at $\mathrm{pH} 7.0,50 \mathrm{mM} \mathrm{KCl})$ heated to $90^{\circ} \mathrm{C}(1-2 \mathrm{~min})$ and slowly cooled to $45^{\circ} \mathrm{C}$. Reverse transcription (RT) reactions were performed in $50 \mathrm{mM}$ Tris- $\mathrm{HCl}$ at $\mathrm{pH} 8.3,75 \mathrm{mM} \mathrm{KCl}, 3 \mathrm{mM} \mathrm{MgCl}_{2} 10 \mathrm{mM}$ DTT with $0.25 \mathrm{mM}$ each dNTP. SuperScript II (Invitrogen, $1 \mu \mathrm{L}$ 200 units) was added and reactions were incubated at $45^{\circ} \mathrm{C}$ for $40 \mathrm{~min}$. For sequencing samples, $1.25 \mathrm{mM}$ of ddATP, ddCTP, ddGTP, or ddTTP was supplied individually to the RT reactions of each sample. Reactions were stopped by ethanol precipitation. cDNA samples were dissolved in $10 \mu \mathrm{L}$ loading dye solution containing $7 \mathrm{M}$ urea, $1 \mathrm{X}$ TBE, bromophenol blue (xylene cyanol blue is omitted as it is detected at $700 \mathrm{~nm}$ ). A small aliquot (1.5$3 \mu \mathrm{L}$ ) of each sample was loaded on an $8 \%$ polyacrylamide gel for separation of cDNAs. Gels were analyzed on to an infrared imaging system Odyssey (LI-COR Biosciences). Bands were detected and quantified directly on the infrared imaging system.

\section{NMR sample preparation}

The mRNA-BWYV 63 nt RNA was prepared by in vitro transcription from an oligonucleotide template containing a $2^{\prime} \mathrm{OmeC}$ and a $2^{\prime} \mathrm{OmeU}$ at the $5^{\prime}$ end (Gaudin et al. 2005). The RNA was then purified by denaturing PAGE. After electroelution and ethanol precipitation, the resuspended RNA was dialyzed against 5 $\mathrm{mM}$ potassium cacodylate at $\mathrm{pH}$ 6.2. NMR sample $(200 \mu \mathrm{M})$ was prepared with $10 \%(\mathrm{v} / \mathrm{v}){ }^{2} \mathrm{H}_{2} \mathrm{O} . \mathrm{MgCl}_{2}$ was added to a final concentration of 1,2 , or $5 \mathrm{mM}$. The pseudoknot sequence (27 nt) (Fig. 1, G12-G38) was chemically synthesized on the $2 \mu \mathrm{mol}$ scale, deprotected, and purified by chromatography on an anionic DEAE column as previously reported (Snoussi et al. 2001). The NMR spectra were measured at $500 \mathrm{MHz}$ using a Varian Inova spectrometer. In the NOE experiment, saturation of the line at $11.3 \mathrm{ppm}$ was achieved using a DANTE sequence.

\section{SUPPLEMENTAL MATERIAL}

Supplemental material can be found at http://www.rnajournal.org. 


\section{ACKNOWLEDGMENTS}

Purified tRNA ${ }^{\text {Gly }}$ and tRNA ${ }^{\text {Asn }}$ were gifts given by Henry Grosjean and Daniel Kern, respectively. We wish to thank Kevin Wilson for the kind gift of the pET24b-fusA vector for His-tagged EF-G. We are also grateful to Olivier Fayet for his support. This work was supported by a "young investigator" grant from the Human Frontier Science Program (HFSP) to D.F. and K.V., and by ANR "young researcher" grant JC05-50413 to S.Y.

Received September 20, 2008; accepted May 26, 2009.

\section{REFERENCES}

Baranov PV, Gesteland RF, Atkins JF. 2002. Recoding: Translational bifurcations in gene expression. Gene 286: 187-201.

Baril M, Dulude D, Steinberg SV, Brakier-Gingras L. 2003. The frameshift stimulatory signal of human immunodeficiency virus type 1 group O is a pseudoknot. J Mol Biol 331: 571-583.

Bertrand C, Prere MF, Gesteland RF, Atkins JF, Fayet O. 2002. Influence of the stacking potential of the base $3^{\prime}$ of tandem shift codons on -1 ribosomal frameshifting used for gene expression. RNA 8: 16-28.

Blinkowa AL, Walker JR. 1990. Programmed ribosomal frameshifting generates the Escherichia coli DNA polymerase III $\gamma$ subunit from within the $\tau$ subunit reading frame. Nucleic Acids Res 18: 17251729.

Brierley I, Digard P, Inglis SC. 1989. Characterization of an efficient coronavirus ribosomal frameshifting signal: Requirement for an RNA pseudoknot. Cell 57: 537-547.

Brunelle MN, Payant C, Lemay G, Brakier-Gingras L. 1999. Expression of the human immunodeficiency virus frameshift signal in a bacterial cell-free system: Influence of an interaction between the ribosome and a stem-loop structure downstream from the slippery site. Nucleic Acids Res 27: 4783-4791.

Chandramouli P, Topf M, Menetret JF, Eswar N, Cannone JJ, Gutell RR, Sali A, Akey CW. 2008. Structure of the mammalian 80S ribosome at $8.7 \AA$ resolution. Structure 16: 535-548.

Chen X, Chamorro M, Lee SI, Shen LX, Hines JV, Tinoco I Jr, Varmus HE. 1995. Structural and functional studies of retroviral RNA pseudoknots involved in ribosomal frameshifting: Nucleotides at the junction of the two stems are important for efficient ribosomal frameshifting. EMBO J 14: 842-852.

Chen G, Wen JD, Tinoco I Jr. 2007. Single-molecule mechanical unfolding and folding of a pseudoknot in human telomerase RNA. RNA 13: 2175-2188.

Cornish PV, Hennig M, Giedroc DP. 2005. A loop 2 cytidine-stem 1 minor groove interaction as a positive determinant for pseudoknotstimulated -1 ribosomal frameshifting. Proc Natl Acad Sci 102: 12694-12699.

Cornish PV, Stammler SN, Giedroc DP. 2006. The global structures of a wild-type and poorly functional plant luteoviral mRNA pseudoknot are essentially identical. RNA 12: 1959-1969.

Du Z, Holland JA, Hansen MR, Giedroc DP, Hoffman DW. 1997. Base-pairings within the RNA pseudoknot associated with the simian retrovirus-1 gag-pro frameshift site. J Mol Biol 270: 464470.

Dulude D, Baril M, Brakier-Gingras L. 2002. Characterization of the frameshift stimulatory signal controlling a programmed -1 ribosomal frameshift in the human immunodeficiency virus type 1. Nucleic Acids Res 30: 5094-5102.

Egli M, Minasov G, Su L, Rich A. 2002. Metal ions and flexibility in a viral RNA pseudoknot at atomic resolution. Proc Natl Acad Sci 99: 4302-4307.

Flower AM, McHenry CS. 1990. The $\gamma$ subunit of DNA polymerase III holoenzyme of Escherichia coli is produced by ribosomal frameshifting. Proc Natl Acad Sci 87: 3713-3717.
Frank J, Agrawal RK. 2000. A ratchet-like intersubunit reorganization of the ribosome during translocation. Nature 406: 318-322.

Garcia A, van Duin J, Pleij CW. 1993. Differential response to frameshift signals in eukaryotic and prokaryotic translational systems. Nucleic Acids Res 21: 401-406.

Gaudin C, Mazauric MH, Traikia M, Guittet E, Yoshizawa S, Fourmy D. 2005. Structure of the RNA signal essential for translational frameshifting in HIV-1. J Mol Biol 349: 1024-1035.

Giedroc DP, Cornish PV. 2009. Frameshifting RNA pseudoknots: Structure and mechanism. Virus Res 139: 193-208.

Giedroc DP, Theimer CA, Nixon PL. 2000. Structure, stability, and function of RNA pseudoknots involved in stimulating ribosomal frameshifting. J Mol Biol 298: 167-185.

Giedroc DP, Cornish PV, Hennig M. 2003. Detection of scalar couplings involving 2 '-hydroxyl protons across hydrogen bonds in a frameshifting mRNA pseudoknot. J Am Chem Soc 125: 4676-4677.

Green L, Kim CH, Bustamante C, Tinoco I Jr. 2008. Characterization of the mechanical unfolding of RNA pseudoknots. J Mol Biol 375: 511-528.

Grentzmann G, Ingram JA, Kelly PJ, Gesteland RF, Atkins JF. 1998. A dual-luciferase reporter system for studying recoding signals. $R N A$ 4: $479-486$.

Habig WH, Pabst MJ, Jakoby WB. 1974. Glutathione S-transferases. The first enzymatic step in mercapturic acid formation. J Biol Chem 249: 7130-7139.

Hansen TM, Reihani SN, Oddershede LB, Sorensen MA. 2007. Correlation between mechanical strength of messenger RNA pseudoknots and ribosomal frameshifting. Proc Natl Acad Sci 104: 583-585.

Hartz D, McPheeters DS, Traut R, Gold L. 1988. Extension inhibition analysis of translation initiation complexes. Methods Enzymol 164: 419-425.

Hartz D, McPheeters DS, Gold L. 1989. Selection of the initiator tRNA by Escherichia coli initiation factors. Genes \& Dev 3: 1899-1912.

Horan LH, Noller HF. 2007. Intersubunit movement is required for ribosomal translocation. Proc Natl Acad Sci 104: 4881-4885.

Huttenhofer A, Noller HF. 1994. Footprinting mRNA-ribosome complexes with chemical probes. EMBO J 13: 3892-3901.

Jacks T, Power MD, Masiarz FR, Luciw PA, Barr PJ, Varmus HE. 1988. Characterization of ribosomal frameshifting in HIV-1 gagpol expression. Nature 331: 280-283.

Jenner L, Rees B, Yusupov M, Yusupova G. 2007. Messenger RNA conformations in the ribosomal $\mathrm{E}$ site revealed by X-ray crystallography. EMBO Rep 8: 846-850.

Joseph S, Noller HF. 1998. EF-G-catalyzed translocation of anticodon stem-loop analogs of transfer RNA in the ribosome. EMBO J 17: 3478-3483.

Kim YG, Su L, Maas S, O’Neill A, Rich A. 1999. Specific mutations in a viral RNA pseudoknot drastically change ribosomal frameshifting efficiency. Proc Natl Acad Sci 96: 14234-14239.

Kim YG, Maas S, Wang SC, Rich A. 2000. Mutational study reveals that tertiary interactions are conserved in ribosomal frameshifting pseudoknots of two luteoviruses. RNA 6: 1157-1165.

Kim YG, Maas S, Rich A. 2001. Comparative mutational analysis of cis-acting RNA signals for translational frameshifting in HIV-1 and HTLV-2. Nucleic Acids Res 29: 1125-1131.

Kollmus H, Honigman A, Panet A, Hauser H. 1994. The sequences of and distance between two cis-acting signals determine the efficiency of ribosomal frameshifting in human immunodeficiency virus type 1 and human T-cell leukemia virus type II in vivo. J Virol 68: 6087-6091.

Kontos H, Napthine S, Brierley I. 2001. Ribosomal pausing at a frameshifter RNA pseudoknot is sensitive to reading phase but shows little correlation with frameshift efficiency. Mol Cell Biol 21: $8657-8670$.

Kurland CG. 1992. Translational accuracy and the fitness of bacteria. Annu Rev Genet 26: 29-50.

Marcheschi RJ, Staple DW, Butcher SE. 2007. Programmed ribosomal frameshifting in SIV is induced by a highly structured RNA stemloop. J Mol Biol 373: 652-663. 
Marczinke B, Fisher R, Vidakovic M, Bloys AJ, Brierley I. 1998. Secondary structure and mutational analysis of the ribosomal frameshift signal of rous sarcoma virus. J Mol Biol 284: 205-225.

Michiels PJ, Versleijen AA, Verlaan PW, Pleij CW, Hilbers CW, Heus HA. 2001. Solution structure of the pseudoknot of SRV-1 RNA, involved in ribosomal frameshifting. J Mol Biol 310: 11091123.

Namy O, Moran SJ, Stuart DI, Gilbert RJ, Brierley I. 2006. A mechanical explanation of RNA pseudoknot function in programmed ribosomal frameshifting. Nature 441: 244-247.

Napthine S, Liphardt J, Bloys A, Routledge S, Brierley I. 1999. The role of RNA pseudoknot stem 1 length in the promotion of efficient -1 ribosomal frameshifting. J Mol Biol 288: 305-320.

Nixon PL, Rangan A, Kim YG, Rich A, Hoffman DW, Hennig M, Giedroc DP. 2002. Solution structure of a luteoviral P1-P2 frameshifting mRNA pseudoknot. J Mol Biol 322: 621-633.

Noller HF, Yusupov MM, Yusupova GZ, Baucom A, Cate JH. 2002. Translocation of tRNA during protein synthesis. FEBS Lett 514: $11-16$.

Ogle JM, Ramakrishnan V. 2005. Structural insights into translational fidelity. Annu Rev Biochem 74: 129-177.

Pallan PS, Marshall WS, Harp J, Jewett FC 3rd, Wawrzak Z, Brown BA 2nd, Rich A, Egli M. 2005. Crystal structure of a luteoviral RNA pseudoknot and model for a minimal ribosomal frameshifting motif. Biochemistry 44: 11315-11322.

Philippe C, Eyermann F, Benard L, Portier C, Ehresmann B, Ehresmann C. 1993. Ribosomal protein S15 from Escherichia coli modulates its own translation by trapping the ribosome on the mRNA initiation loading site. Proc Natl Acad Sci 90: 4394-4398.

Plant EP, Dinman JD. 2005. Torsional restraint: A new twist on frameshifting pseudoknots. Nucleic Acids Res 33: 1825-1833.

Plant EP, Dinman JD. 2006. Comparative study of the effects of heptameric slippery site composition on -1 frameshifting among different eukaryotic systems. RNA 12: 666-673.

Plant EP, Jacobs KL, Harger JW, Meskauskas A, Jacobs JL, Baxter JL, Petrov AN, Dinman JD. 2003. The 9- $\AA$ solution: How mRNA pseudoknots promote efficient programmed -1 ribosomal frameshifting. RNA 9: 168-174.

Pleij CW, Rietveld K, Bosch L. 1985. A new principle of RNA folding based on pseudoknotting. Nucleic Acids Res 13: 1717-1731.

Powers T, Noller HF. 1991. A functional pseudoknot in $16 \mathrm{~S}$ ribosomal RNA. EMBO J 10: 2203-2214.

Puglisi JD, Wyatt JR, Tinoco I Jr. 1988. A pseudoknotted RNA oligonucleotide. Nature 331: 283-286.

Ringquist S, MacDonald M, Gibson T, Gold L. 1993. Nature of the ribosomal mRNA track: Analysis of ribosome-binding sites containing different sequences and secondary structures. Biochemistry 32: 10254-10262.

Schuwirth BS, Borovinskaya MA, Hau CW, Zhang W, Vila-Sanjurjo A, Holton JM, Cate JH. 2005. Structures of the bacterial ribosome at $3.5 \AA$ A resolution. Science 310: 827-834.

Seol Y, Skinner GM, Visscher K. 2004. Elastic properties of a singlestranded charged homopolymeric ribonucleotide. Phys Rev Lett 93: 118102. doi: 10.1103/PhysRevLett.93.118102.
Shen LX, Tinoco I Jr. 1995. The structure of an RNA pseudoknot that causes efficient frameshifting in mouse mammary tumor virus. J Mol Biol 247: 963-978.

Snoussi K, Nonin-Lecomte S, Leroy JL. 2001. The RNA i-motif. J Mol Biol 309: 139-153.

Spahn CM, Beckmann R, Eswar N, Penczek PA, Sali A, Blobel G, Frank J. 2001. Structure of the 80 S ribosome from Saccharomyces cerevisiae-tRNA-ribosome and subunit-subunit interactions. Cell 107: 373-386.

Spedding G, Gluick TC, Draper DE. 1993. Ribosome initiation complex formation with the pseudoknotted alpha operon messenger RNA. J Mol Biol 229: 609-622.

Spiegel PC, Ermolenko DN, Noller HF. 2007. Elongation factor G stabilizes the hybrid-state conformation of the 70S ribosome. RNA 13: $1473-1482$.

Staple DW, Butcher SE. 2005a. Pseudoknots: RNA structures with diverse functions. PLoS Biol 3: e213. doi: 10.1371/journal.pbio. 0030213.

Staple DW, Butcher SE. 2005b. Solution structure and thermodynamic investigation of the HIV-1 frameshift inducing element. J Mol Biol 349: 1011-1023.

Stern S, Moazed D, Noller HF. 1988. Structural analysis of RNA using chemical and enzymatic probing monitored by primer extension. Methods Enzymol 164: 481-489.

Su L, Chen L, Egli M, Berger JM, Rich A. 1999. Minor groove RNA triplex in the crystal structure of a ribosomal frameshifting viral pseudoknot. Nat Struct Biol 6: 285-292.

Takyar S, Hickerson RP, Noller HF. 2005. mRNA helicase activity of the ribosome. Cell 120: 49-58.

Tsuchihashi Z, Kornberg A. 1990. Translational frameshifting generates the gamma subunit of DNA polymerase III holoenzyme. Proc Natl Acad Sci 87: 2516-2520.

Valle M, Zavialov A, Sengupta J, Rawat U, Ehrenberg M, Frank J. 2003. Locking and unlocking of ribosomal motions. Cell 114: 123134

Weiss RB, Dunn DM, Shuh M, Atkins JF, Gesteland RF. 1989. E. coli ribosomes re-phase on retroviral frameshift signals at rates ranging from 2 to 50 percent. New Biol 1: 159-169.

Wen JD, Lancaster L, Hodges C, Zeri AC, Yoshimura SH, Noller HF, Bustamante C, Tinoco I. 2008. Following translation by single ribosomes one codon at a time. Nature 452: 598-603.

Wilson KS, Nechifor R. 2004. Interactions of translational factor EF-G with the bacterial ribosome before and after mRNA translocation. J Mol Biol 337: 15-30.

Ying BW, Fourmy D, Yoshizawa S. 2007. Substitution of the use of radioactivity by fluorescence for biochemical studies of RNA. RNA 13: 2042-2050.

Yoshizawa S, Fourmy D, Puglisi JD. 1999. Recognition of the codonanticodon helix by ribosomal RNA. Science 285: 1722-1725.

Yusupova GZ, Yusupov MM, Cate JH, Noller HF. 2001. The path of messenger RNA through the ribosome. Cell 106: 233-241.

Yusupova G, Jenner L, Rees B, Moras D, Yusupov M. 2006. Structural basis for messenger RNA movement on the ribosome. Nature 444: 391-394. 

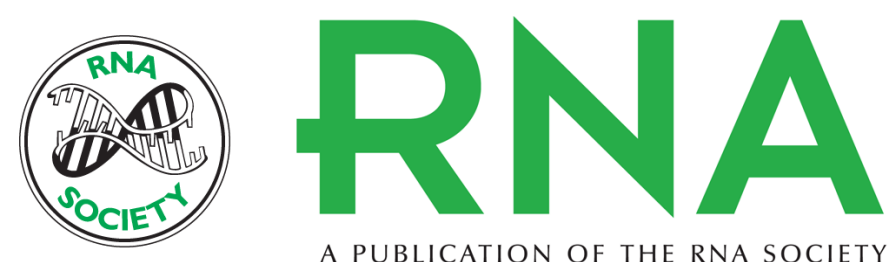

A PUBLICATION OF THE RNA SOCIETY

\section{Footprinting analysis of BWYV pseudoknot-ribosome complexes}

Marie-Hélène Mazauric, Jean-Louis Leroy, Koen Visscher, et al.

RNA 2009 15: 1775-1786 originally published online July 22, 2009

Access the most recent version at doi:10.1261/rna.1385409

Supplemental

Material

References

\section{License}

Email Alerting Service
http://rnajournal.cshlp.org/content/suppl/2009/07/22/rna.1385409.DC1

This article cites 76 articles, 23 of which can be accessed free at: http://rnajournal.cshlp.org/content/15/9/1775.full.html\#ref-list-1 